\title{
Effects Of Risks On Online Consumers' Purchasing Behavior: Are They Risk-Averse Or Risk-Taking?
}

Seung Hwan Kim, Indiana University of Pennsylvania, USA Framarz Byramjee, Indiana University of Pennsylvania, USA

\begin{abstract}
Since the beginning of e-commerce, trustworthiness of commercial web sites has been a constant issue, and, very likely, it will continue to be. When an online shopper cannot trust a web site where he or she intends to make a purchase, the online shopper would perceive a risk of transactional security and a risk of privacy of personal information. In regard to this perceived risk in online transactions, this study is set out to find the change in the level of perceived risk in Business-to-Consumer (B2C) e-commerce and to test whether or not consumers trust a webcentric company at their first visit to the company's web site. Two major findings of this study are that about one third of those surveyed for the study feel an increased risk in B2C online transactions over the previous year, and that absolute majority of them have never or rarely shopped on a web site they are not familiar with. It is further found that even an attractive deal cannot affect the risk-averse behavior of online shopping. From the findings of the study, it is concluded that risk-averse online shopping behavior is a manifestation of increased perceived risk in B2C online transactions.
\end{abstract}

Keywords: E-Commerce; B2C; Online Trust; Perceived Risk; Risk Sensitive; Risk Averse

\section{INTRODUCTION}

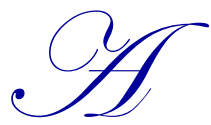

fter its introduction into the market in 1993, e-commerce has grown exponentially and is expected to grow at an increasing rate. Business-to-Consumer (B2C) e-commerce has been contributing significantly to the growth of e-commerce; however, there are still many concerns that keep online consumers from completing transactions over B2C websites. Those concerns include issues of security, privacy, merchant legitimacy, order fulfillment, and so on. Thus, it is necessary to find ways to minimize those concerns and fears in order to maintain current customers and create future e-commerce customers. This is especially true for web-centric companies that do business solely online without having physical facilities, as it is imperative that they develop customer trust quickly in their online business practices.

These days, more and more consumers shop online around the clock and around the world. Thus, the statement, (the) Internet is still far from achieving its potential as an e-marketplace, by some researchers, sounds quite reasonable. One major reason for that statement comes from a fact that significant numbers of potential consumers are reluctant to engage in transactions online due to lack of consumer trust in e-commerce, which implies, in one particular respect, many potential consumers perceive that releasing private financial information over online net is still significantly risky.

\section{LITERATURE REVIEW}

Since the start of e-commerce, it has always been an issue how to conduct a business online in a secure and private manner. Recently, with an increasing number of cases of identity theft and/or financial fraud committed online, performing a secure and private transaction in this environment has become a more serious concern. 
Compared with traditional in-store shopping, online shopping is only possible when trust is assumed or gained. This is because online transactions occur from remote locations in a non-face-to-face environment, and require personal information such as credit card number, name, address, phone number, and even a social security number, depending on the type of transaction.

It is obvious that most of online consumers' concerns are derived from a lack of trust in e-commerce. In the following section, previous research on trust in an e-commerce context is reviewed.

\section{Trust in E-Commerce}

One of the most significant studies on trust in e-commerce was published by Salam et al. in 2005. They explored the theoretical framework of trust in the generic B2C e-commerce context. The framework explored in the study highlighted that "trust in the context of e-commerce was a complex --- phenomenon reflecting technological, behavioral, social, psychological, and organizational interactions among human and nonhuman technological agents" (p. 77). They found that, in online B2C relationships, though technology itself was a necessary component, technology alone could not suffice to build long-term trust between consumers and online businesses. They suggested that, in order to promote online consumers' positive spending behavior, various interventions should be devised that affect various aspects of online shopping behavior.

Alongside with Salam et al.'s framework, Ratnasingam (2005) divided trust in a business-to-business (B2B) e-commerce into two distinctive components: technology trust and relationship trust. He related technology trust to "institutional structural assurance and security mechanisms embedded in e-commerce technology," and referred relationship trust to "trading partners' competence, predictability, reliability, and benevolence in the ecommerce relationship."

Another insight into the relationship between trust and e-commerce is found in the work of Bellman et al. (1999). Addressing privacy and/or security issues in a B2C circumstance, Bellman et al. found a few surprises in their research. One of the surprises was that consumers considered online security and privacy issues less and less important; therefore those issues were losing influence on online consumers' shopping behavior. Another surprising finding from the study was that when consumers were shopping online, they valued time savings significantly more than monetary savings. Based on this result, it was suggested that success of online businesses would hinge more on how convenient it was to save time than on how much money was saved by shopping on their web sites.

Another research question addressed from a critical point of view is whether online users' asserted privacy concerns correspond to their actual behavior. Despite the online users' alleged privacy concern on B2C e-commerce, it was little known if online users acted according to their stated privacy concerns. Berendt et al. (2005) placed their focus on how online users' privacy attitudes resulted in actual behavior in an online environment. Suggested in their study was that many online users expressed high privacy concerns and further stated privacy preferences; however, they did not live up to their opinions on online privacy. According to the study, online users were not able to monitor and control their behaviors regarding privacy matters, especially when they were involved in an online transaction where they were tempted by entertaining material or when some sort of rewards were offered in exchange for private information. The authors of the study contended that, particularly in these kinds of circumstances, privacy disclosures or statements wouldn't make any difference in online behavior.

Extending from the online users' actual behavior that is incongruent with their asserted privacy concerns, Mauldin et al. (2002) further stressed that, "comfort with the Internet, general intent to buy online, and web site design played significant roles in influencing purchase intention," (p. 48) while "information risk generally did not significantly influence purchase intention" (p. 48).

Since it has been reviewed how the issue of trust has affected e-commerce and how the trust issue has changed over time in e-commerce, it is focused next on how online shoppers deal with risks that are inevitable in virtual reality. 


\section{Effects of Risks on B2C E-Commerce}

One of early relevant study on risk-bearing attitudes was done by Kahneman et al. (1979). By an individual's propensity towards risk-bearing, they classified online shopping behaviors into two distinctive attitudes: risk-taking and risk-averse. They adopted the general norm that risk-takers would weigh benefits of online shopping more heavily than the potential harms from e-commerce, but that risk-averse individuals would prefer brick-andmortar retailers for personal and direct interfaces with the retailers. Regarding the attitudes to risks in e-commerce, Chernev (2003) characterized risk-takers and risk-averse people by their respective behavioral traits; risk-takers, departing from the current state, are willing to benefit from the positive potentials of uncertainties such that they are rather entrepreneurial and promoting growth, however, risk-averse group is the one who want to stay away from negative potentials of uncertainties by keeping status quo. In one step forward of behavioral traits, Helmut (1993) upheld that whether online shoppers adapt to the new environment well or not would, after all, depend on their inherent preference towards risk.

Moving in the direction of how online consumers overcome perceived risks and build trust in B2C transactions, McCole et al.'s, Andrews et al.'s, Chen et al.'s, and Chung et al.'s research are noteworthy. McCole et al. (2002) found that, after repeatedly using the Internet as their transactional medium, consumers realized more of the benefits of engaging in transactions through the cyber space. Andrews et al. (2012) examined the relationship among perceived risk online, attitudes towards online purchase, and intentions to purchase online. Their research revealed that, while perceived risk online was inversely related to attitudes online, attitudes online was directly related to intentions to purchase online. Chen et al. (2007) shared the basically same relationship among the three variables as well. They further found that, among the trust factors they examined, trusts derived from third-party assurance and from cultural environment were the most positively influential on online purchase intentions. Chung et al.'s work (2010) brought out the results from other perspectives that, although a website's characteristics, such as website design, convenience to shop, and informativeness, had positive effects on online shopping, the strongest effect came from the website's communication, which then led to word-of-mouth advocating of the site. It was the word-of-mouth advocating that, they found, reduced perceived risks in online shopping. Tsai et al. (2010) also found similar results to Chung et al.'s, and Pavlou's (2003), using technology acceptance model, suggested eventually resembling implications to those. As another measure for online shoppers to deal with information risks, Bandyopadhyay (2009) said online shoppers might try to control the way in which online companies collect and use their private information.

Getting closer to the current research subject, here reviewed is another research by Koufaris et al. (2004). They explained how new online customers developed initial trust in a web-based company when the customers visited the web-based company for the first time. Their field study confirmed some of the findings of other researches on risk and trust in e-commerce; the common finding was that perception of web site usefulness and easiness and perceived security control played significant antecedent roles to develop initial trust. Besides this finding, they had their own finding that perceived reputation of the company and willingness and ability to customize products and/or services had significant and positive effects on initial-trust building. They concluded that all the characteristics of web site to promote initial trust were to reduce perceived risk, or 'emotions of uncertainty.'

In regard to risk-sensitivity in $\mathrm{B} 2 \mathrm{C}$ online transactions, this study is set out to find the change in the level of perceived risk in $\mathrm{B} 2 \mathrm{C}$ e-commerce and to test whether or not consumers trust a web-centric company at their first visit to the company's web site. Below presented are a research model of the study and research questions developed for each of the research points. 


\section{RESEARCH DEVELOPMENT}

\section{Research Model}

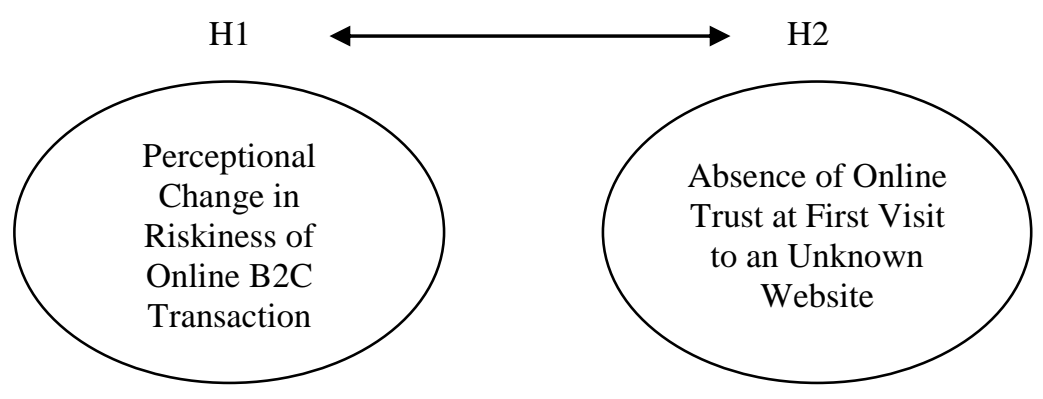

\section{Hypotheses Development}

The current level of online consumers' overall assurance concerns is going to be checked in comparison with that of a year ago. The first hypothesis is posited in this connection.

Hypothesis 1 (H1): In terms of informational privacy and transactional security, online consumers perceive that online transactions have higher risks than in the past.

By the standard of whether or not an online company has physical existence, online companies are broadly classified into two kinds. One is a click-and-mortar company, which is so called because the company exists both in the online world and in the physical world. Barnes and Noble and Best Buy are examples of click-and-mortar companies. The other kind of online company is the web-centric company that exists only online. Examples of such online companies are eBay and Amazon.com.

Among web-centric companies, some companies have established themselves on their web sites' trustworthiness through consumers' shopping experience, whereas other companies may be lacking enough consumers' shopping experience to be trusted by them. In this regard, following is proposed.

Hypothesis 2 (H2): When online consumers first encounter a web site of an online-only company they have never heard of before, they are not likely to trust that web site.

As indicated in the research model with bidirectional arrows between the two hypotheses, next, it was tested whether these hypotheses epistemologically hold each other together or showed unrelated results between them.

\section{Subjects and Survey Development}

\section{Subjects and Survey Medium}

The research was administered to more than 300 undergraduate and graduate students. The participants were students in a state-supported university in Midwest in the United States. In an effort to help make the subjects as representative of the general public as possible, the subjects were sought from every college unit in the university.

Paper surveys were utilized, and, to encourage active participation in the survey, questionnaires were distributed and completed in class. Subjects were asked questions about their ordinary online purchase experiences to test the hypotheses. In addition to the questions, demographic information of the surveyed subjects was gathered.

\section{Manipulation Check and Pilot Test}

According to American Marketing Association, a manipulation check is defined as "a measurement that is taken in an experiment to make sure that subjects accurately perceived the actual changes in the treatment variable." 
In a questionnaire, manipulation check also works as a crosscheck that a respondent understands a question and answers the question with attention paid to it. In constructing a survey of this study, manipulation checks were built into the survey in a way that every key question was rephrased and re-asked with a different response scale. In this study, manipulation checks played a crucial role as a device that helped screen and clean conflicting data.

The initial version of the survey was tested on twelve randomly selected subjects. The pilot subjects were graduate students who were capable of critiquing the initial survey. Then, feedback or suggestions from the pilot subjects were reflected in revisions of the survey that improved the understandability of questions and accuracy of measurement scales.

\section{Survey Questions for Hypotheses Testing}

For the tests of the hypotheses, two types of questions were asked; one type of questions was dichotomous, and the other type of questions was on a six-point Likert-type scale.

\section{DATA COLLECTION}

308 copies of questionnaires were prepared to collect data. During the pilot test, the time was measured that it took the pilot subjects to complete one questionnaire. On average, it took five minutes to do the survey.

\section{Amount and Time of Data Collected}

308 sets of questionnaires were assembled and used for data collection. Out of the 308 questionnaires, 6 were not returned ( $2 \%$ loss rate), and the remaining 302 questionnaires were entered into data analysis. The data were collected over a 41-day period (02/20/2008-03/31/2008).

\section{Atmosphere of Data Collection}

In every class data were sought in, the instructor for the class allotted his/her class time for the students to participate in the survey. Before questionnaires were distributed to the students, every instructor made a strong encouraging statement and stayed throughout the data-collection time as if he/she was running the survey.

Except for two classes, the survey was administered at the beginning of class after a few minutes of classstarting time. In one of the two classes where data were collected at the end of class, extra points were set up as an incentive to induce a high rate of participation in the survey as well. In the other class, the instructor closed his lecture early enough in order to allow sufficient time for the students to complete the survey during the class time.

Besides the positive facets of a highly encouraging atmosphere in which data were collected, the experimental conditions in which data were captured was controlled to be the same, or very similar, for all classes. There seemed no significant conditional differences observed among the classes, whether or not there was an incentive for the participation. During the data-screening phase, this was purposely checked and confirmed.

\section{Demographic Information}

Basic demographic information of the subjects is provided below.

Table 1: Age

\begin{tabular}{|l|c|c|c|}
\hline \multicolumn{1}{|c|}{ Range } & Frequency & Percent & Cumulative Percent \\
\hline-20 & 88 & 29.1 & 29.1 \\
$21-25$ & 168 & 55.6 & 84.7 \\
$26-30$ & 33 & 11.0 & 95.7 \\
$31-35$ & 6 & 2.0 & 97.7 \\
$36-$ & 7 & 2.3 & 100 \\
\hline Total & 302 & 100 & \\
\hline
\end{tabular}


Table 2: Gender

\begin{tabular}{|l|c|c|}
\hline \multicolumn{1}{|c|}{ Gender } & Frequency & Percent \\
\hline Female & 126 & 41.7 \\
Male & 176 & 58.3 \\
\hline Total & 302 & 100.0 \\
\hline
\end{tabular}

\section{CONCEPTUAL FRAMEWORK OF METHODOLOGY}

The operationalization of the variables and their appropriately suited measurement scales was decided based on the domain definitions for each of the constructs. The two major constructs being employed in this research are 'Online Purchase Behavior' and 'Intention to Purchase Online' - both these constructs and their underlying empirical variables have been treated as surrogate measures for consumers' risk-bearing propensity when shopping online. The empirical indicators which adequately reflected the domain of each respective construct, thereby serving to reliably measure the construct, were corroborated by experts to assess their face validity and thereby the constructs' content validity (Nunnally, 1978).

The 'Online Purchase Behavior' construct is being reflected in measurement by variables like consumers' concern about safety of online transactions being riskier now than a year ago, consumer's concern about their personal information being released to unwanted parties when buying something on the Internet, consumers' decision to purchase online due to privacy concerns regarding personal information, consumers' decision to purchase something on the Internet due to being unsure of the security of the transaction, and consumers' concern for personal information security in online purchase now as compared to a year ago. These five variables served as the empirical indicators to cohesively measure the domain of this construct. They were measured on continuous numerical Likert-type scales with suitably chosen anchors for measuring the logic intended for the items in accordance with the correspondence rules being implemented for the measurement. Beyond this main construct, consumers' online purchase behavior was also further assessed by two independent items such as whether the respondent has ever bought anything on the Internet, and whether the respondent has made a purchase on a website that was newly posted on the Internet the very first time they entered that site - these two items were also measures along continuous numerical Likert-type scales with suitably chosen anchors and correspondence rules for maintaining the logic.

The 'Intention to Purchase Online' construct is being reflected in measurement by variables like consumers' intention to buy an item on a never-seen-nor-heard-of website if the deal being offered online seems attractive, if the decision is dependent on how the respondent feels about the legitimacy of the website after having browsed through it for a while, and if the decision is dependent on how the respondent feels about the integrity of the website after spending some time browsing through it. These three variables served as the empirical indicators to cohesively measure the domain of this construct. They were measured on continuous numerical Likert-type scales with suitably chosen anchors for measuring the logic intended for the items in accordance with the correspondence rules being implemented for the measurement. Beyond this main construct, consumers' intention to purchase online was also further assessed by two independent items such as whether the respondent would basically ever exhibit an intention to purchase anything online on a never-seen-nor-heard-of website, and whether the respondent will think of buying things more on the Internet in the future than in the past - these two items were also measures along continuous numerical Likert-type scales with suitably chosen anchors and correspondence rules for maintaining the logic.

The critical research design aspect ensured and rigorously enforced throughout the measures and their respective measurement scales implemented in this study was to maintain the correspondence rule of the scales in every single question/item/measure as it primarily reflects how each numerical value on the measurement scales with their appropriately designed scale anchors connects the logic of assessment to what is being measured in that respective item/question. Accordingly, all the above described empirical indicators measured along their suitably worded scales bearing the appropriate scale anchors and correspondence rules helped ensure that respondents' riskbearing propensity was being reflected via the sample respondent's intention to purchase online as well as their online purchase behavior. Thus, as respondents (consumers) inherently perceive lower levels of risk as inherent traits driving their consumption attitude, they would exhibit higher patterns of online shopping behavior and also 
higher intentions to purchase online, while as respondents (consumers) inherently perceive higher levels of risk as inherent traits driving their consumption attitude, they would exhibit lower patterns of online shopping behavior and also lower intentions to purchase online. As behavior and intention in human schema influencing consumer attitude and psyche tend to affect each other, this study attempts to test the effects of each variable/construct on the other.

\section{Data-Analysis Procedures}

The two main constructs of the research were subject to exploratory factor analysis in SPSS 19.0 in order to determine their convergent and discriminant validity, thereby validating the measures. The procedure respectively included within-factors type factor analysis as well as between-factors type factor analysis to judge/establish the unidimensionality of each of the constructs. Then, the measurement scales for both of these constructs were also tested for their internal consistency through reliability analysis in SPSS 19.0. Lastly, the hypotheses posited in the research were tested via their respective regressions in SPSS 19.0.

Additionally, the differences between groups of respondents in terms of gender effects between males and females (as per the demographic variables) with regard to their online shopping attitude (behavior as well as intention) for reflecting perceived risk were tested by analysis of variance (one-way ANOVA) runs in SPSS 19.0.

\section{Factor Analyses and Reliability Analysis for the Constructs}

Exploratory factor analysis via principal components factoring as well as principal axis factoring techniques was conducted for each construct. The Kaizer-Meyer-Olkin (KMO) Measure of Sampling Adequacy values were considerably high in all cases, and the Bartlett's Test of Sphericity was also found significant in all cases, implying that factor analysis could be performed on the data (Tabachnick \& Fidell, 2001). Further, the sample size of 302 compared to the 12 main numerically measurable variables along continuous scales in the survey yielded greater than 10:1 ratio of sample size to number of variables, which well justified the suitability of factor analytic procedures on the data (Tabachnick \& Fidell, 2001). Loadings below 0.4 were suppressed throughout, so as to view a cleaner loadings' structure.

Upon running the within-factor type factor analysis for each construct, the empirical indicators for each construct loaded well onto their respective constructs. The two Component Matrix tables from the SPSS outputs for each of the constructs, 'Online Purchase Behavior' and 'Intention to Purchase Online,' are shown below. Thus, these items did adequately represent and measure the underlying conceptual domain of their respective construct, thereby helping to establish good convergent validity for each construct.

Table 3: Component Matrix ${ }^{\mathrm{a}}$

\begin{tabular}{|l|c|}
\hline & Component \\
\cline { 2 - 2 } & $\mathbf{1}$ \\
\hline VAR13_c & .901 \\
VAR13_d & .892 \\
VAR13_b & .581 \\
\hline
\end{tabular}

Extraction Method: Principal Component Analysis. ${ }^{a} 1$ components extracted.

Table 4: Component Matrix ${ }^{a}$

\begin{tabular}{|l|c|}
\hline & Component \\
\cline { 2 - 2 } & \multicolumn{1}{|c|}{ 1 } \\
\hline VAR11 & .854 \\
VAR10 & .823 \\
VAR9 & .768 \\
VAR12 & .741 \\
VAR7 & .730 \\
\hline
\end{tabular}

Extraction Method: Principal Component Analysis. ${ }^{\mathrm{a}} 1$ components extracted.

Upon running the between-factors type factor analysis between the two constructs, the five measures of 'Online Purchase Behavior' and the three measures of 'Intention to Purchase Online' exhibited unique respective 
loadings, as shown below in the Component Matrix table from the SPSS output. Thus, this resultant segregated loadings structure between the two constructs helped to establish good discriminant validity between the constructs.

Table 5: Component Matrix ${ }^{\mathrm{a}}$

\begin{tabular}{|l|c|c|}
\hline \multirow{2}{*}{} & \multicolumn{2}{|c|}{ Component } \\
\cline { 2 - 3 } & $\mathbf{1}$ & $\mathbf{2}$ \\
\hline VAR11 & .837 & \\
VAR10 & .814 & \\
VAR912 & .750 & \\
VAR7 & .727 & .864 \\
VAR13_c & .704 & .855 \\
VAR13_d & & .503 \\
VAR13_b & & \\
\hline
\end{tabular}

Extraction Method: Principal Component Analysis. ${ }^{\mathrm{a}} 2$ components extracted.

Reliability analysis was then performed on each of the constructs to test for their internal consistency. The following table summarizes the Cronbach's Alpha reliability coefficient for each construct. The high Alpha values (close to or greater than 0.7), as per Nunnally and Bernstein (1994), indicate that internal consistency of the factors is high; thereby all items measuring their respective construct do homogeneously belong to that construct. Thus, the two constructs in the study represent strong measures.

Table 6: Reliability Analysis

\begin{tabular}{|l|c|}
\hline \multicolumn{1}{|c|}{ Dimension/Construct } & Cronbach's Alpha \\
\hline Online Purchase Behavior (OPB) [5 items] & 0.808 \\
Intention to Purchase Online (IPO_dli) [3 items] & 0.699 \\
\hline
\end{tabular}

\section{Hypotheses/Relationships Testing}

After having established the validity and reliability of the measures, the hypotheses posited in the study were tested using their respective regressions. In case of both the composite constructs, their summed averages of respective item-measures were used to represent the construct scores. The table below shows the summarized results of all the sets of regressions conducted between conceptually connected variables as guided by our theoretical sensemaking for determining the consumers' decision-making schema in the online shopping environment. The standardized beta coefficients, $t$-values, and $p$ (sig.)-values were examined to ascertain the significance of variables in the regressions (Hair, Black, Babin, Anderson, \& Tatham, 2006); for each case, a beta coefficient with the absolute value of its $t$-statistic being greater than 2.011 and its $p$ (sig.) value being less than 0.05 implying that the particular independent variable bears a statistically significant effect on the respective dependent variable at the 5\% level of significance.

Table 7: Regression Analysis

\begin{tabular}{|l|c|c|c|c|c|}
\hline \multicolumn{1}{|c|}{ Dep. Var. } & Indep. Var. & Stdzd. $\boldsymbol{\beta}$ & $\boldsymbol{t}$ - value & $\boldsymbol{p}$ (sig.) & Test $\boldsymbol{F}$ \\
\hline OPB & IPO_dli & 0.153 & 2.677 & $0.008 *$ & $7.167 *$ \\
IPO_dli & OPB & 0.153 & 2.677 & $0.008 *$ & $7.167 *$ \\
$13 \_a$ & 14 & 0.257 & 4.598 & $0.000 *$ & $21.141 *$ \\
14 & $13 \_a$ & 0.257 & 4.598 & $0.000 *$ & $21.141 *$ \\
5 & 6 & 0.342 & 6.295 & $0.000 *$ & $39.627 *$ \\
6 & 5 & 0.342 & 6.295 & $0.000 *$ & $39.627 *$ \\
\hline
\end{tabular}

* implies coefficient is statistically significant at the $5 \%$ level of significance.

In case of the pair of regressions run between the 'Online Purchase Behavior' [OPB] and 'Intention to Purchase Online' [IPO_dli] constructs, a statistically significant relationship emerges in both cases, showing that intention and behavior are strongly affecting each other.

In case of the pair of regressions run between the two conceptually linked variables suggesting consumer attitude regarding whether the respondent has made a purchase on a website that was newly posted on the Internet 
the very first time they entered that site [14] (serving as a measure of online purchase behavior) and whether the respondent would basically ever exhibit an intention to purchase anything online on a never-seen-nor-heard-of website [13_a] (serving as a measure of intention to purchase online), a statistically significant relationship emerges in both cases, showing that intention and behavior are strongly affecting each other.

In case of the pair of regressions run between the two conceptually linked variables suggesting consumer attitude regarding whether the respondent has ever bought anything on the Internet [5] (serving as a measure of online purchase behavior) and whether the respondent will think of buying things more on the Internet in the future than in the past [6] (serving as a measure of intention to purchase online), a statistically significant relationship emerges in both cases, showing that intention and behavior are strongly affecting each other.

These results, in aggregation, lend support to our main research conjecture that consumers' intention to purchase online is driven by their online purchase behavior, and that their online purchase behavior is in turn influenced by their intention to purchase online; thus, this recursive relationship between intention and behavior is primarily affected by the individuals' inherent trait of risk-bearing propensity - in accordance, the level of risk perceived by consumers as an attitudinal tendency in the online shopping environment manifests in their online shopping attitude through their online shopping behavior as well as their intention to shop online. Thus, the measurement and analyses yielded in this study show that consumers' online purchasing behavior and intention, each as a function of perceived risk in online shopping, land up significantly and substantively affecting each other.

\section{Group-Differences Testing for Gender-Based Effects}

The differences between groups of respondents in terms of gender effects between males and females (as per the demographic variables) with regard to their online shopping attitude (behavior as well as intention) as surrogates for consumers' risk-perception in online shopping were tested by two analysis of variance (one-way ANOVA) runs in SPSS 19.0.

The one-way ANOVA result between 'Online Purchase Behavior' [OPB] and Gender was found statistically significant $(p<0.05)$, showing that males and females do exhibit varying tendencies in their perceived risk-bearing attitude that accordingly makes them differ in their online purchase behavior. As per the output, the mean [OPB] score for the 'females' group was 2.3492, while the mean [OPB] score for the 'males' group was 1.9830. In accordance with the correspondence rules of measurement employed within the measures and scales whereby a consumer tends to display lesser online shopping affinity as he/she perceives higher risk when having to shop online, and vice versa, a higher mean value conveys that group to possess a higher level of perceived risk in the online shopping mode. Thus, this finding shows that females seem to show a higher level of perceived risk in their online purchase behavior as compared to males.

The one-way ANOVA result between 'Intention to Purchase Online' [IPO_dli] and Gender was also found statistically significant $(p<0.05)$, showing that males and females do exhibit varying tendencies in their perceived risk-bearing attitude that accordingly makes them differ in their intention to purchase online. As per the output, the mean [IPO_dli] score for the 'females' group was 1.8386, while the mean [IPO_dli] score for the 'males' group was 1.6288. In accordance with the correspondence rules of measurement employed within the measures and scales whereby a consumer tends to display lesser online shopping affinity as he/she perceives higher risk when intending to shop online, and vice versa, a higher mean value conveys that group to possess a higher level of perceived risk in the online shopping mode. Thus, this finding shows that females seem to show a higher level of perceived risk in their intention to purchase online as compared to males.

\section{DISCUSSION AND CONCLUSION}

To summarize in plain words and numbers, more than one third of the subject pool (37\%) felt an increased risk in $\mathrm{B} 2 \mathrm{C}$ online transactions over the previous year $(\mathrm{H} 1)$, and this perception then translated to their online shopping behavior in an amplified fashion (relationship between $\mathrm{H} 1$ and $\mathrm{H} 2$ ). The absolute majority of them (88\%) have never or rarely shopped on a web site they are not familiar with (H2). This trend was found true even when they came across a favorable deal, until they established a base of trustworthiness with the unknown site. These 
findings led to the conclusion of the study that high majority of online consumers were very sensitive to trust issues; therefore, they were very likely risk-averse rather than risk-taking. Between genders, this conclusion holds true more of females than males.

As a reference for future research on online trust in B2C environments, it would be worth addressing other areas that could positively affect trust in B2C e-commerce. This suggestion derives from another piece of finding of the study; when online consumers had little concerns about the products they were buying, they were willing to pay higher prices in the real online world than the lowest price that they found online for the same product.

\section{LIMITATIONS}

The results of the study were intended to bring out practical and relevant outcomes to B2C e-commerce stakeholders. Nonetheless, as is almost always true in any other study, this study had to face its own limits regarding the findings.

First, readers should be aware of the degree to which subjects of the study were representative of the general public, which extends to the scope of generalizablility of what the study found. Second, there are multiple studies in business and non-business areas that have reported a high correlation between intentions and actual behaviors. In those studies, it was signified concurrently that there were significant portions of intentions not explained by or realized in actual behaviors. Having these probable limitations in mind, readers of this study should comprehend the findings of this study accordingly.

\section{AUTHOR INFORMATION}

Dr. Seung Hwan Kim got master's and doctorate in accounting in 1999 and 2008, respectively, both from Southern Illinois University Carbondale. He currently teaches accounting at Indiana University of Pennsylvania. His main research interests lie in e-commerce, accounting information systems, and accounting education. E-mail: seung.kim@iup.edu (Corresponding author)

Dr. Framarz Byramjee is Associate Professor of Marketing, Eberly College of Business and Information Technology, Indiana University of Pennsylvania, Indiana, Pennsylvania, USA. E-mail: byramjee@iup.edu

\section{REFERENCES}

1. Andrews, L., \& Bianchi, C. (2012). Risk, trust, and consumer online purchasing behavior: A Chilean perspective. International Marketing Review, 29(3), 253-275.

2. Bandyopadhyay, S. (2009). Antecedents and consequences of consumers' online privacy concerns. Journal of Business and Economics Research, 7(3), 41-48.

3. Bellman, S., Lohse, G.L., \& Johnson, E.J. (1999). Predictors of online buying behavior. Communications of the ACM, 42(12), 32-38.

4. Berendt, B., Günther, O., \& Spiekermann, S. (2005). Privacy in e-commerce: Stated preferences vs. actual behavior. Communications of the ACM, 48(4), 101-106.

5. Bester, H. (1994). Price commitment in search markets. Journal of Economic Behavior \& Organization, 25(1), 109-120.

6. Chen, Y.-H., \& Barnes, S. (2007). Initial trust and online buyer behaviour. Industrial Management \& Data Systems, 107(1), 21-36.

7. Chernev, A. (2003). Goal orientation and consumer preference for the status quo. Journal of Consumer Research, 31(3), 557-565.

8. Chung, K.-H., \& Shin, J.-I. (2010). The antecedents and consequents of relationship quality in internet shopping. Asia Pacific Journal of Marketing and Logistics, 22(4), 473-491.

9. Joseph, H., Black, W., Babin, B., Anderson, R., \& Tatham, R. (2006). Multivariate data analysis. New Jersey: Prentice Hall.

10. Kahneman, D., \& Tversky, A. (1979). Prospect theory: An analysis of decision under risk. Econometrica, 47(2), 263-292. 
11. Koufaris, M., \& Hampton-Sosa, W. (2004). The development of initial trust in an online company by new customers. Information and Management, 41, 377-397.

12. Mauldin, E., \& Arunachalam V. (2002). An experimental examination of alternative forms of web assurance for business-to-consumer e-commerce. Journal of Information Systems, 16(1), 33-54.

13. McCole, P., \& Palmer, A. (2002). Transaction frequency and trust in internet buying behavior. Irish Marketing Review, 15(2), 35-51.

14. Nunnally, J. (1978). Psychometric theory. New York: McGraw-Hill.

15. Nunnally, J., \& Bernstein, I. (1994). Psychometric theory (3rd ed.). New York: McGraw-Hill.

16. Pavlou, P. (2003). Consumer acceptance of electronic commerce: integrating trust and risk with the technology acceptance model. International Journal of Electronic Commerce, 7(3), 69-103.

17. Ratnasingam, P. (2005). E-commerce relationships: The impact of trust on relationship continuity. International Journal of Commerce \& Management, 15(1), 1-16.

18. Salam, A. F., Iyer, L., Palvia, P., \& Singh, R. (2005). Trust in e-commerce. Communications of ACM, 48(2), 73-77.

19. Tabachnick, B., \& Fidell, L. (2001). Using multivariate statistics. New Jersey: Prentice Hall.

20. Tsai, Y. C., \& Yeh, T. C. (2010). Perceived risk of information security and privacy in online shopping: A study of environmentally sustainable products. African Journal of Business Management, 4(18), 40574066 . 
NOTES 